\title{
Diuron tolerance and potential degradation by pelagic microbiomes in the Great Barrier Reef lagoon
}

Florent E Angly, Olga Pantos, Thomas C Morgan, Virginia Rich, Hemerson Tonin, David G Bourne, Philip Mercurio, Andrew P Negri, Gene W Tyson

Diuron is a herbicide commonly used in agricultural areas where excess application causes it to leach into rivers, reach sensitive marine environments like the Great Barrier Reef (GBR) lagoon and pose risks to marine life. To investigate the impact of diuron on whole prokaryotic communities, that underpin the marine food web and are integral to coral reef health, GBR lagoon water was incubated with diuron at environmentally-relevant concentration $(8 \mu \mathrm{g} / \mathrm{L})$, and sequenced at specific time points over the following year. $16 \mathrm{~S}$ rRNA gene amplicon profiling revealed no significant short- or long-term effect of diuron on microbiome structure. The relative abundance of prokaryotic phototrophs was not significantly altered by diuron, which suggests that they were largely tolerant at this concentration. Assembly of a metagenome derived from waters sampled at a similar location in the GBR lagoon did not reveal the presence of mutations in the cyanobacterial photosystem that could explain diuron tolerance. However, resident phages displayed several variants of this gene and could potentially play a role in tolerance acquisition. Slow biodegradation of diuron was reported in the incubation flasks, but no correlation with the relative abundance of heterotrophs was evident. Analysis of metagenomic reads support the hypothesis that previously uncharacterized hydrolases carried by low-abundance species may mediate herbicide degradation in the GBR lagoon. Overall, this study offers evidence that pelagic phototrophs of the GBR lagoon may be more tolerant of diuron than other tropical organisms, and that heterotrophs in the microbial seed bank may have the potential to degrade diuron and alleviate local anthropogenic stresses to inshore GBR ecosystems. 
1 Diuron tolerance and potential degradation by pelagic microbiomes in the Great Barrier Reef lagoon

4 Florent E Angly 1*, Olga Pantos ${ }^{1,2}$, Thomas C Morgan ${ }^{1}$, Virginia Rich ${ }^{3,4}$, 5 Hemerson Tonin 5, David G Bourne 5, Philip Mercurio 5,6, Andrew P Negri 5, Gene

$8{ }^{1}$ Australian Centre for Ecogenomics, The University of Queensland, St Lucia, Queensland,

9 Australia

$10{ }^{2}$ Global Change Institute, The University of Queensland, St Lucia, Queensland, Australia

$11{ }^{3}$ Department of Soil, Water and Environmental Science, The University of Arizona, Tucson,

12 Arizona, United States of America

$13{ }^{4}$ Current affiliation: Microbiology Department, The Ohio State University, Columbus, Ohio,

14 United States of America ${ }^{5}$ Australian Institute of Marine Science, Townsville, Queensland,

15 Australia $^{6}$ National Research Centre for Environmental Toxicology, The University of

16 Queensland, Coopers Plains, Queensland, Australia

$17{ }^{*}$ Corresponding author: florent.angly@gmail.com 


\section{Abstract}

19 Diuron is a herbicide commonly used in agricultural areas where excess application causes it to

20 leach into rivers, reach sensitive marine environments like the Great Barrier Reef (GBR) lagoon

21 and pose risks to marine life. To investigate the impact of diuron on whole prokaryotic

22 communities, that underpin the marine food web and are integral to coral reef health, GBR

23 lagoon water was incubated with diuron at environmentally-relevant concentration $(8 \mu \mathrm{g} / \mathrm{L})$, and

24 sequenced at specific time points over the following year. 16S rRNA gene amplicon profiling

25 revealed no significant short- or long-term effect of diuron on microbiome structure. The relative

26 abundance of prokaryotic phototrophs was not significantly altered by diuron, which suggests

27 that they were largely tolerant at this concentration. Assembly of a metagenome derived from

28 waters sampled at a similar location in the GBR lagoon did not reveal the presence of mutations

29 in the cyanobacterial photosystem that could explain diuron tolerance. However, resident phages

30 displayed several variants of this gene and could potentially play a role in tolerance acquisition.

31 Slow biodegradation of diuron was reported in the incubation flasks, but no correlation with the

32 relative abundance of heterotrophs was evident. Analysis of metagenomic reads support the

33 hypothesis that previously uncharacterized hydrolases carried by low-abundance species may

34 mediate herbicide degradation in the GBR lagoon. Overall, this study offers evidence that pelagic

35 phototrophs of the GBR lagoon may be more tolerant of diuron than other tropical organisms,

36 and that heterotrophs in the microbial seed bank may have the potential to degrade diuron and

37 alleviate local anthropogenic stresses to inshore GBR ecosystems. 


\section{Introduction}

39 Coral reefs are very rich and diverse ecosystems, though due to both local and global anthropogenic disturbances, they are in a state of gradual decline (Pandolfi et al., 2003). Local impacts such as coastal pollution (Brodie et al., 2012) and overfishing (De’ath et al., 2012) affect both the reef macrobiota (Fabricius, 2005; Sandin et al., 2008) and the microorganisms in their associated microbiomes (Dinsdale et al., 2008; Thurber et al., 2009; Webster et al., 2011). Microorganisms not only underpin the marine food web and system function (Azam et al., 1983; Fenchel, 2008), but also form intimate relationships with corals that are essential for their health (Rohwer et al., 2002; Lesser et al., 2004; Lema, Willis \& Bourne, 2012). Hence, changes to microbiome structure and function can compromise the health of coral reefs and their ability to recover from stresses (Ainsworth, Thurber \& Gates, 2010; Hughes et al., 2010).

Fishing impact is limited across the Great Barrier Reef (GBR), but otherwise oligotrophic inshore coastal habitats (Schaffelke et al., 2012) are subject to pollution from land runoff of agricultural, industrial and domestic origin (Packett et al., 2009; Brodie et al., 2012). For example, herbicides that are used to control weeds in the sugarcane plantations of Queensland have been detected in the waterways of the catchments (McMahon et al., 2005; Mitchell, Brodie \& White, 2005; Shaw \& Müller, 2005), intertidal sediments, and in the waters surrounding inshore coral reefs (Shaw \& Müller, 2005; Lewis et al., 2009). The herbicide diuron, or 3-(3,4-dichlorophenyl)-1,1dimethylurea (DCMU), is consistently detected in the GBR lagoon (Haynes, Müller \& Carter, 2000; Shaw et al., 2010; Kennedy et al., 2012b), exceeding the Australian and New Zealand guideline trigger value of $0.2 \mu \mathrm{g} / \mathrm{L}$ at some sites (Smith et al., 2012). Diuron is an effective broad-spectrum herbicide due to its ability to inhibit the photosystem II (PSII) complex of photosynthetic organisms (Metz et al., 1986). Consequently, it poses risks to a wide range of marine eukaryotes including invertebrates (Bellas et al., 2005; Mai et al., 2013), seagrasses (Haynes et al., 2000; Flores et al., 2013), fishes (Mhadhbi \& Beiras, 2012), diatoms (Legrand et al., 2006; Magnusson, Heimann \& Negri, 2008) and microalgae, both benthic (Magnusson et al., 2012) and in endosymbiotic relationship with corals (Jones et al., 2003; Jones, 2004; Shaw, photo-degradation (Okamura, 2002; Moncada, 2004; Mercurio et al., 2015) results in its accumulation in the marine environment, particularly in sediments (Haynes, Mueller \& Carter, 2000; Balakrishnan, Takeda \& Sakugawa, 2012; Xu et al., 2013). 
69 In addition to its effects on eukaryotes, diuron is also toxic to bacteria. Low concentrations of

70 diuron (1.6-23 $\mu \mathrm{g} / \mathrm{L}$ ) impairs the photosynthesis of phototrophs such as cyanobacteria (Allen et

71 al., 1983; Deng, Gao \& Sun, 2012), while very high concentrations $\left(1 \times 10^{6} \mu \mathrm{g} / \mathrm{L}\right)$ inhibit the

72 growth of bacterial heterotrophs (Faÿ et al., 2010). Consequently, exposure to a pulse of diuron

73 through a flooding event can significantly alter microbiome structure (Tlili et al., 2008) and

74 decrease microbial abundance (Ricart et al., 2009). Conversely, diuron exposure can also increase

75 bacterial abundance in wastewater treatment ponds (Sumpono et al., 2003), likely due to

76 heterotrophic bacteria taking advantage of the release of organic compounds by organisms

77 susceptible to diuron, such as diatoms (Proia et al., 2011). An alternative explanation is that some

78 bacteria are able to metabolize diuron and use it as an energy source (Dellamatrice \& Monteiro,

79 2004), as seen in soil, sediments and sludge (Cullington \& Walker, 1999; Dellamatrice \&

80 Monteiro, 2004; Sørensen, Albers \& Aamand, 2008; Stasinakis et al., 2009; Pesce et al., 2012).

81 This biodegradation is catalyzed by phenylurea hydrolases (PuhAB) (Turnbull et al., 2001;

82 Khurana et al., 2009) and proceeds faster than degradation by abiotic means (Cullington \&

83 Walker, 1999; Dellamatrice \& Monteiro, 2004; Sørensen, Albers \& Aamand, 2008; Stasinakis et

84 al., 2009; Pesce et al., 2010). Microorganisms are therefore regularly employed in herbicide

85 pollution remediation technologies (Villaverde et al., 2012; Safi, Awad \& El-Nahhal, 2014).

86 A recent study found that microbial community variations in the GBR lagoon are primarily

87 driven by riverine effluents (Angly et al., 2015) and a year-long seawater simulation experiment

88 presented evidence that microorganisms play a role in the biodegradation of a wide range of PSII

89 herbicides in this region (Mercurio et al., 2015). Although the community-wide effects of diuron

90 on marine microorganisms are not characterized, this research suggests that pelagic microbiomes

91 may protect coral reef and seagrass ecosystems by degrading this herbicide. In the present study,

92 we hypothesized that diuron significantly affects the composition of these microbiomes by

93 specifically: i) inhibiting phototrophs in the short-term; and ii) sustaining the long-term growth of

94 selected heterotrophs that have the potential to metabolize it, leading to the herbicide's

95 disappearance. To investigate these hypotheses, we collected samples from the simulation study

96 of Mercurio et al. (2015) and an inshore GBR location and characterized their microbiomes

97 (Archaea and Bacteria) using high-throughput 16S rRNA amplicon profiling and metagenomics. 
98 Materials \& Methods

\section{Cape Ferguson diuron incubations}

100 Mercurio et al. (2015) collected surface seawater (24 L) in sterile containers in the tropical dry 101 season (15 May 2012) from Cape Ferguson, QLD, Australia (latitude -19.2673297, longitude

102 147.0591537) (Figure S1), a site that is $\sim 17 \mathrm{~km}$ downstream from the Haughton River mouth and

103 where diuron is consistently reported in the wet season (Lewis et al., 2009; Kennedy et al.,

104 2012a,b). The investigators passed seawater through $20 \mu \mathrm{m}$ impact filters, dispensed it in $500 \mathrm{~mL}$

105 glass flasks and incubated it during 365 days on a shaking platform at $25^{\circ} \mathrm{C}$ either in the dark or

106 in the light (12:12 light day cycle with $40 \mu \mathrm{mol}$ photons $\left.\mathrm{m}^{-2} \mathrm{~s}^{-1}\right)$, and with or without amendment

107 of diuron (at the ecologically relevant concentration of $8 \mu \mathrm{g} / \mathrm{L}$ ) (Lewis et al., 2009; Kennedy et

108 al., 2012a,b) (Figure S2 A and B). The investigators performed each experimental treatment in

109 triplicate (12 flasks in total) and monitored diuron concentration for each flask over the life of the

110 incubation. For more details of the experimental set up and diuron degradation results, see

111 Mercurio et al. (2015).

112 In the present study, we collected subsamples $(705 \mu \mathrm{L})$ from each flask at day 0, 2, 7, 28, 120 and

113365 for 16S rRNA gene analysis. Each subsample was collected with a pipette after thoroughly

114 shaking the flask, $5 \mu \mathrm{L}$ were stained with $5 \mu \mathrm{L}$ of DAPI $(1 \mu \mathrm{g} / \mathrm{ml})$ in the dark for $15 \mathrm{~min}$, and

115 observed with a Nikon Ci-L epifluorescence microscope (Figure S2 C). This confirmed the

116 presence of DNA-containing cells, a prerequisite for sequencing.

117 Total DNA was extracted by first centrifuging each sample at 13,000 $\times \mathrm{g}$ for $30 \mathrm{~min}$. Each

118 resulting pellet was then resuspended in $20 \mu \mathrm{L}$ microLYSIS-Plus DNA release buffer (Microzone,

119 UK) for $30 \mathrm{~min}$ at room temperature and incubated using a thermal cycler following the

120 manufacturer's tough cell lysis protocol $\left(65^{\circ} \mathrm{C}\right.$ for $15 \mathrm{~min} ; 96^{\circ} \mathrm{C}$ for $2 \mathrm{~min} ; 65^{\circ} \mathrm{C}$ for $4 \mathrm{~min} ; 96^{\circ} \mathrm{C}$

121 for $1 \mathrm{~min}$; $65^{\circ} \mathrm{C}$ for $1 \mathrm{~min} ; 96^{\circ} \mathrm{C}$ for $30 \mathrm{sec}$ ). Control of the absence of microLYSIS-Plus reagent

122 contamination by foreign DNA was carried out by adding a blank sample, containing only the

123 microLYSIS-Plus buffer (without template DNA).

124 Microbial amplicons were generated by PCR-amplifying the V6 to V8 variable regions of the 16S

125 rRNA gene in the total DNA using a universal primer set targeting Archaea and Bacteria

126 (iTAG926F and iTAG1392wR primers) according to the protocol in Dove et al. (2013). These

127 amplicons were paired-end sequenced on an Illumina MiSeq instrument at the Australian Centre

128 for Ecogenomics (ACE). 


\section{Microbiome profiling}

130 Amplicon reads were processed using Hitman (https://github.com/fangly/hitman, described in

131 Angly et al., 2015), a bioinformatic workflow based around the UPARSE methodology (Edgar,

132 2013). The following parameters were used: trimming length of $250 \mathrm{bp}$, minimum quality value

133 of 7 (16 for HiFi sequences), maximum number of expected errors of 3.0 (0.5 for HiFi

134 sequences), OTU clustering at 97\% identity (species-level), GOLD (Bernal, Ear \& Kyrpides,

135 2001) as the reference database for chimera detection, rarefaction depth of 20,000 counts,

136 minimum global alignment of 95\% identity (genus-level) for taxonomic annotation using the

137 merged Silva (Quast et al., 2012) and Greengenes (McDonald et al., 2012) databases

138 (https://github.com/fangly/merge gg silva), gene-copy number correction with CopyRighter

139 (Angly et al., 2014), and exclusion of taxa matching “Eukaryota*” or “*Chloroplast*”.

140 Rarefaction curves were produced using Bio-Community's bc_accumulate (Angly, Fields \&

141 Tyson, 2014) with 100 random subsets. After taxonomic assignments and gene-copy number

142 correction within Hitman, calculation of $\alpha$-diversity was performed using Bio-Community

143 bc_measure_alpha at the selected rarefaction depth. A few OTUs of interest, that could not be

144 taxonomically assigned with Hitman, were classified by the RDP Classifier at 80\% confidence

145 (Cole et al., 2009), and Silva's SINA with 95\% identity (Quast et al., 2012).

\section{Statistical analysis}

147 The significance of changes in taxon relative abundance between sampling points were evaluated

148 using LEfSe (Segata et al., 2011). The effects of incubation regimen on microbial community

149 structure was assessed by Hellinger-transforming the microbial profiles and analyzing them using

150 the R language (R Foundation for Statistical Computing, Vienna, Austria), specifically using the

151 capscale(), adonis() and rda() functions of the vegan packages (Dixon, 2003), for PCoA,

152 PERMANOVA and RDA analysis respectively.

\section{Dunk Island metagenome preparation}

154 An additional seawater sample was collected in the tropical dry season (13 October 2009), north

155 of Dunk Island, QLD, Australia (latitude -17.9242918, longitude 146.1429637) (Figure S1). This

156 site is $\sim 15 \mathrm{~km}$ downstream from the Tully River mouth, and exposed to diuron and other PSII

157 herbicides in comparable concentrations as the Cape Ferguson site (Lewis et al., 2009; Kennedy

158 et al., 2012a,b). A $20 \mathrm{~L}$ volume was taken from a depth of $5 \mathrm{~m}$ and pre-filtered through a $2.7 \mu \mathrm{m}$

159 Whatman GF/D filter and a $1.6 \mu \mathrm{m}$ Whatman GF/A filter to remove particles and most eukaryotic 
160 microorganisms. The filtrate was then passed through a $0.22 \mu \mathrm{m}$ Millipore Express Plus filter to

161 capture the bacterial and archaeal fraction. The filters were folded in half, cells inward, added to a

162 tube containing $20 \mathrm{ml}$ of lysis buffer ( $40 \mathrm{mM} \mathrm{Na} 2$ EDTA, $50 \mathrm{mM}$ Tris pH 8.3 and $0.73 \mathrm{M}$ sucrose,

163 sterilized), stored shipboard at $-20^{\circ} \mathrm{C}$ and transferred to $-80^{\circ} \mathrm{C}$ on land.

164 DNA was extracted from the filter using a modified method from Suzuki et al. (2004). In brief,

165 the filter was thawed on ice, added $6 \mathrm{ml}$ of lysis buffer with $5 \mathrm{mg} / \mathrm{ml}$ lysozyme and the tube was

166 incubated for $30 \mathrm{~min}$ at $37^{\circ} \mathrm{C}$, while rotating at $10 \mathrm{rpm}$. Proteinase $\mathrm{K}(1.1 \mathrm{mg} / \mathrm{mL}$ final

167 concentration) and 10\% sodium dodecyl sulfate (1.1\% final concentration) were added and the

168 sample was incubated at $55^{\circ} \mathrm{C}$ for $2 \mathrm{~h}$, with rotation. The lysate was split in half and DNA was

169 extracted from each using two rounds of phenol:chloroform:isoamyl alcohol (25:24:1, pH 8.0),

170 then one round of chloroform:isoamyl alcohol (24:1). Aqueous phases were pooled and frozen

171 overnight at $-20^{\circ} \mathrm{C}$. The aqueous phase was then cleaned by passage of $15 \mathrm{ml}$ at a time through

172 Amicon Ultra-15 100 kDa spin unit (EMD Millipore, Billerica, Massachusetts, USA). The filter

173 was washed once with $8 \mathrm{ml}$ of Tris EDTA buffer (TE, 10mM, pH 8.0) and recovered with $50 \mu \mathrm{L}$

174 of TE (1mM, pH 8.0). DNA was then further cleaned by precipitation with $70 \%$ ethanol, the

175 pellet was washed once with 70\% ethanol, air dried, and resuspended in $100 \mu \mathrm{L}$ TE, for a total

176 yield of $37 \mu \mathrm{g}$ DNA. The resulting DNA was sequenced on an Illumina (Solexa) Genome

177 Analyzer II instrument at the University of Arizona, producing 25.4 million pairs of 101 bp long

178 reads.

179 Read-centric metagenomic screening for phenylurea hydrolases

180 The Dunk Island metagenomic read pairs were cleaned by removing Illumina adapters with

181 TRIMMOMATIC, merged using PEAR (but keeping unmerged read pairs), 5' end quality-

182 trimmed at the first nucleotide below Q13 and filtered to remove sequences smaller than $60 \mathrm{bp}$

183 using TRIMMOMATIC. The resulting quality-controlled reads were compared to all known

184 PuhAB phenylurea hydrolase proteins (GI 218764925, 598062302 and 218764905), belonging to

185 the metal-dependent amidohydrolase superfamily (Turnbull et al., 2001; Khurana et al., 2009),

186 using BLASTX (Camacho et al., 2009). The BLAST database also included 55 other closely-

187 related proteins, including other herbicide hydrolases, to ensure the specificity of the results: the

188 MolA molinate hydrolase (Sugrue et al., 2015) (GenBank FN985594), four LibA linuron

189 hydrolases (Bers et al., 2011, 2013) (GenBank JN104629, JN104630, JN104631 and JN104633)

190 and 50 proteins from the metal dependent amidohydrolase superfamily (GI 18655481, 7245484,

19123200144, 23200220, 3892028, 22218649, 14719683, 13786715, 28948588, 30749918, 999767, 
192 24987382, 27574194, 30750126, 24371617, 40787177, 15966345, 16124371, 5817646,

193 22972062, 21222419, 23058081, 24216335, 3912984, 1709955, 33595951, 27375360,

194 27378941, 22987263, 23105179, 3914514, 16763233, 27377792, 2829648, 18311855,

195 15612748, 17540282, 17548772, 38108196, 15791459, 15528804, 40063581 and 24371695).

196 Significant similarities (E-value < 1e-6) were extracted and their alignment to the most similar

197 proteins was visually inspected using Jalview (Waterhouse et al., 2009). The putative taxonomic

198 affiliation of the Puh-like proteins was established by comparing the metagenomic reads to the

199 NCBI nt database using TBLASTX.

200 Under the assumption that each distinct identified PuhAB protein is encoded by a different

201 species (the three known Puh proteins are encoded on three distinct genomes), we approximated

202 this species' relative abundance as: $A \approx R \times G \times 10^{-4} /(P \times M \times L) \%$, where $R$ is the number of

203 reads matching puhAB, $M$ is the number of screened metagenomic reads $(22,927,633), L$ is the

204 average read length $\mathrm{L}(93.7 \mathrm{bp}), P$ is the average length of the puhAB genes (1,376 bp), $G$ is the

205 average genome length in marine microbiomes (2.58 Mbp) (Angly et al., 2009), and $S$ is the

206 number of species in inshore GBR water column (643 OTUs in the diuron incubation

207 experiment).

208

209

210

211

212

213

214

215

216

217

218

219

220

221

\section{Contig-centric metagenomic screening for photosystem genes}

For this analysis, the Dunk Island metagenomic raw read pairs were cleaned with

TRIMMOMATIC by removing Illumina adapters, deleting reads with uncalled bases, truncating their 5 ' end to a final length of $80 \mathrm{bp}$, and removing smaller reads. The data were assembled using IDBA-UD (Peng et al., 2012), and translated into their 6 possible reading frames. The hmmsearch tool of HMMER3 (Eddy, 2011) was employed to look for photosystem B proteins in these translated scaffolds using the TIGR001151 PsbA hidden Markov Model profile of TIGRFAMs (Haft, Selengut \& White, 2003). A maximum E-value of 1e-50 was used to retrieve significant matches and their alignment was visualized in Jalview. The taxonomic affiliation of the scaffolds matching PsbA was determined by best BLASTN similarity against the NCBI nr database (minimum identity of 70\% over a minimum alignment length of 1,200 bp, i.e. the length of PsbA + 40 amino acids). Nesoni (https://github.com/Victorian-Bioinformatics-

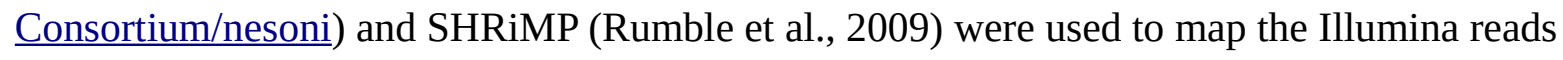
against the metagenomic scaffolds and call single nucleotide polymorphisms (SNPs). 
222 Results \& Discussion

223 Microbial dynamics in Cape Ferguson diuron incubation

224 Mercurio et al. (2015) collected seawater during the tropical dry season at Cape Ferguson, an

225 inshore region of the GBR (Figure S1 and S2), to conduct a year-long diuron incubation

226 experiment. In the present study, the 16S rRNA amplicon sequencing of 72 samples taken at set

227 time points from the incubation flasks generated a total of 4.96 million read pairs (NCBI

228 accession PRJNA276057). Processing through the Hitman bioinformatic pipeline resulted in 3.83

229 million high-quality sequences (77.3\% of the initial amount). Rarefaction at a depth of 20,000

230 counts per sample provided a sequencing depth-independent view of the diversity of the samples

231 (Figure S3, Table S1), collectively containing 4,743 distinct OTUs (97\% identity level).

232 The taxonomic affiliation conducted by best global alignment against the Greengenes database

233 and subsequent gene-copy number correction (Angly et al., 2014) permitted estimation of

234 changes in the relative abundance of prokaryotic taxa over time (Figure S4). When averaging the

235 replicates (Figure 1, Figure S5), the most abundant taxa at the start of the incubation (day 0)

236 included the orders Rickettsiales (19\%) and Synechococcales (14\% average relative abundance),

237 from the Cyanobacteria and Proteobacteria phyla, respectively. The microbiomes were marked by

238 a succession of various taxa over time, as seen in previous work (Fierer et al., 2010). For

239 example, Sphingomonadales increased significantly from an initial average of 0.38\% relative

240 abundance (day 0) to dominate the communities with $30 \%$ at day 2 (LEfSe; $\alpha<0.05$ ).

241 Rhodobacterales-affiliated sequences increased significantly, reaching a maximum relative

242 abundance of $36 \%$ on average a week after the start of the incubation (day 7) (LEfSe; $\alpha<0.05$ ),

243 and subsequently significantly decreased until day 120 (LEfSe; $\alpha<0.05$ ). At the end of the

244 incubation experiment (day 365), Oceanospirillales were very abundant in the control flasks

245 exposed to light, while Thiotrichales dominated the samples incubated in the dark (both control

246 and diuron-treated).

247 Three predominant OTUs (OTU 12, 13 and 20) characteristic of the flasks kept in the dark could

248 not be assigned to a taxonomic group. Further identification efforts using the RDP Classifier and

249 Silva's SINA suggest that they all belong to the Proteobacteria phylum, more precisely to the

250 Salinisphaera, Coxiella and GR-WP33-30 taxa (Table S2). The genus Salinisphaera includes a

251 recently sequenced species that is adapted to environments with fluctuating conditions (Antunes

252 et al., 2011), while the genus Coxiella contains a single species that is highly resistant to 
253 environmental stresses such as temperature, osmotic pressure and ultraviolet radiation (Voth \&

254 Heinzen, 2007), and representatives of the order GR-WP33-30 were detected in uranium mines

255 (Selenska-Pobell \& Radeva, 2004). The robustness of these taxa may be responsible for their

256 success in the dark and likely oligotrophic conditions of the incubation flasks.

\section{Effect of diuron on microbial profiles}

258 The diuron measurements made by Mercurio et al. (2015) in the incubation flasks ranged from an 259 initial 8.77 $\mu \mathrm{g} / \mathrm{L}$ (dark conditions, replicate R4) down to $3.78 \mu \mathrm{g} / \mathrm{L}$ (light conditions, replicate R3)

260 after one year of incubation. Here, we included the diuron concentration of each individual flask

261 as an input for a constrained ordination (Figure 2), which demonstrated a significant influence of

262 incubation time and light exposure, but not of diuron concentrations on the microbial profiles

263 (PERMANOVA, $\mathrm{p}<0.05$ ). Dissection of the differences between diuron-treated and control flasks

264 for each individual sampling day, PCoA (Figure S6) confirmed that diuron did not affect

265 microbiome composition significantly (PERMANOVA, $\mathrm{p}<0.05$ ).

\section{Resistance of photosynthetic bacteria to diuron}

267 Some phototrophic bacteria are inhibited by diuron, while others are insensitive. For example,

268 photosystems I and II exist in Cyanobacteria and vascular plants, and physiological experiments

269 have demonstrated binding of diuron on the cyanobacterial photosystem II, leading to

270 photosynthesis inhibition (Allen et al., 1983; Gadkari, 1988; Brusslan \& Haselkorn, 1989; Deng,

271 Gao \& Sun, 2012). Conversely, diuron does not bind to the photosynthetic reaction center of

272 purple bacteria and they may remain unaffected (Sinning, 1992). We thus hypothesized that the

273 majority of phototrophic prokaryotes in the incubation experiment would be affected by diuron

274 toxicity, resulting in their rapid decline.

275 Cyanobacteria and purple bacteria such as Rhodobacteraceae were prevalent in the incubation

276 flasks, but their relative abundance did not decline between day 0 and 28 (Figure 2, Figure S6 A-

277 D), despite the presence of more than $8.45 \mu \mathrm{g} / \mathrm{L}$ diuron on average during this period, a

278 concentration that markedly inhibits the photosynthesis of diatoms and green algae (Magnusson,

279 Heimann \& Negri, 2008; Magnusson et al., 2012). This supports previous reports that

280 Cyanobacteria are less sensitive to PSII herbicides than eukaryotic phototrophs (Lürling \&

281 Roessink, 2006). The relative insensitivity of Cyanobacteria in our dataset could be explained by

282 pollution-induced community tolerance (PICT) following chronic exposure to herbicides, which

283 was previously reported for biofilms in a French river (Tlili et al., 2008, 2011) and for periphyton 
284 (a mixture of detritus, algae and microorganisms growing on submerged surfaces) in the GBR

285 lagoon (Magnusson et al., 2012) and in a Swedish fjord (Molander \& Blanck, 1992). The

286 mechanism underpinning this tolerance for diuron is not yet elucidated, but may be related to the

287 evolution and enrichment of high-turnover variants of the PsbA protein upon which diuron and

288 other PSII herbicides such as irgarol 1051 bind (Eriksson et al., 2009; Deng, Gao \& Sun, 2012).

289 Metagenomic analysis was undertaken to explore the presence of PsbA variants and the potential

290 for diuron resistance in the GBR lagoon. Since the samples collected during the Cape Ferguson

291 incubation experiment contained too little biomass for comprehensive metagenomic sequencing,

292 we prepared a metagenome from a sample collected during the tropical dry season at Dunk

293 Island, another inshore GBR location (NCBI accession SRR1819825). Weather, river effluent and

294 diuron exposure data indicate that the Dunk Island and Cape Ferguson samples were both

295 representative of the GBR lagoon during the dry season, when the effects of riverine floodwaters

296 are minimal (Text S1, Table S3-6), and therefore comparable (Angly et al., 2015). The Dunk

297 Island metagenome was assembled into 74,000 scaffolds (771 bp average length, 879 bp N50)

298 from which all putative PsbA protein sequences were identified (Figure 3). The introduction of

299 Val219 and Ser264 mutations in PsbA confers PSII herbicide resistance (Bettini et al., 1987;

300 Mengistu et al., 2000) and mutations in the PsbA PEST domain (rich in rich in amino-acids P, E,

301 S and T) were previously correlated with resistance in the environment (Eriksson et al., 2009).

302 But none of these mutations were detected in the Dunk Island scaffolds of Cyanobacteria

303 (Synechococcus and Prochlorococcus). Further, a total of 24,900 reads mapped onto the $12.9 \mathrm{~kb}$

304 long Prochlorococcus scaffold, but no SNPs could be identified within the psbA gene.

305 PEST sequence type 11 (RETTENESANAGYK), representing a PEST type hypothesized to

306 confer irgarol tolerance to the Swedish fjord microbiomes (Eriksson et al., 2009), was detected in

307 the metagenomic scaffolds (Figure 3). However, BLASTN analyses suggest that this sequence

308 was part of a eukaryotic genome (100\% query coverage and $100 \%$ identity to Micromonas, a

309 member of the Prasinophyceae class) (Worden et al., 2009). The Prasinophyceae are composed of

310 unicellular photosynthetic green algae and Micromonas $(<2 \mu \mathrm{m})$ could have passed through the

$3111.6 \mu \mathrm{m}$ wide pores of the filters used during metagenome preparation. Similarly, the Swedish

312 fjord sequencing read containing PEST type 11 (accession AM933747) best matched a eukaryotic

313 genome from another subdivision of the Prasinophyceae (100\% query coverage and 99\% identity

314 to the Pycnococcaceae family). This suggests that PEST type 11 is a general feature of the

315 Prasinophyceae genome and, at least in the present study, not an adaptive mutation of Bacteria 
316 and Archaea to protect against PSII herbicides.

317 BLASTN investigation of the metagenomic scaffolds from Dunk Island encoding PsbA revealed

318 that they were not only prokaryotic and eukaryotic. Most of them (14 out of 24) were of viral

319 origin (Figure 3), and 9 out of the 11 PEST types identified in the present study matched some

320 carried by cyanophages. This large PEST type diversity and the propensity of phages to transfer

321 genes to and from their hosts (lateral gene transfer) raises the possibility that cyanophages steer

322 the stability of PsbA in their hosts (Lindell et al., 2004; Zeidner et al., 2005; Sharon et al., 2007).

323 Future research should consider how this may influence the tolerance of phototrophs to PSII

324 herbicides.

325 Potential for degradation by heterotrophic bacteria

326 Another hypothesis formulated in this study was that specific heterotrophic populations would

327 carry genes for the degradation of diuron and take advantage of this resource, leading to an

328 increase of their relative abundance over time. During the one-year Cape Ferguson incubation

329 experiment, Mercurio et al. (2015) reported 15-31\% diuron degradation. They attributed this

330 slow degradation in part to prokaryotic breakdown but, in the present work, we found no

331 significant association between diuron-treated incubation flasks and heterotrophic abundance

332 between day 28 and 365 (Figure 2, Figure S6 D-F). While this evidence goes against our

333 hypothesis of rapid heterotrophic degradation, a similar marine incubation study also detected a

334 lack of diuron degradation over a shorter 42 d timeframe (Thomas, McHugh \& Waldock, 2002).

335 Experiments using microbiomes from soil (Attaway, Paynter \& Camper, 1982; Cullington \&

336 Walker, 1999; Widehem et al., 2002; Dellamatrice \& Monteiro, 2004; Ngigi et al., 2011),

337 activated sludge (Stasinakis et al., 2009) and freshwater sediments (Ellis \& Camper, 1982; Pesce

338 et al., 2010) have demonstrated that diuron can be degraded by bacteria belonging to the genera

339 Pseudomonas (el-Deeb et al., 2000), Arthrobacter (Turnbull et al., 2001; Villaverde et al., 2012),

340 Mycobacterium (Khurana et al., 2009), Variovorax (Sørensen, Albers \& Aamand, 2008), Bacillus,

341 Vagococcus and Burkholderia (Ngigi et al., 2011). Sequences affiliated with some of these taxa,

342 specifically Burkholderia and Pseudomonas, were detected at $\sim 4 \%$ in our marine incubations, but

343 their relative abundance did not change significantly in response to long-term exposure to this

344 herbicide (Figure 2, Figure S6), suggesting that exposure to diuron and any potential degradation

345 did not alter their evolutionary fitness.

346 To explore the reasons for the lack of rapid heterotrophic degradation of diuron in the incubation 
347 experiment and the potential for diuron degradation in the GBR lagoon at large, we looked for

348 phenylurea hydrolase genes, known to degrade diuron (Turnbull et al., 2001; Khurana et al., 349 2009), in the reads of the Dunk Island metagenome. Two reads had BLASTX similarities to a 350 protein database covering the metal-dependent amidohydrolase superfamily. These reads were 351 more similar to PuhB than to other PSII hydrolases and proteins from the same superfamily, with 352 a high 51\% amino acid identity over 54 amino acids (Figure S7) indicative of the presence of 353 potential phenylurea hydrolase homologs (Rost, 1999). Despite the short length of these

354 metagenomic reads and the potential sequencing errors they contain, the proteins identified here 355 may represent novel phenylurea or other PSII hydrolases, whose existence has previously been 356 suggested (Pesce et al., 2012). Further research will be needed to characterize the sequence, 357 structure and function of this protein and thus confirm this hypothesis. The five top scoring 358 similarities of one of these metagenomic reads (TBLASTX, $>=98 \%$ query cover, E value $<=2 \mathrm{e}-$ 359 22) suggest that a bacterium from the Bacteroidetes phylum (Flavobacteriia or Cytophagia order) 360 encodes this PuhB-like protein, while the five top scoring similarities for the other read 361 (TBLASTX, >=97\% identity, E value <=5e-12) did not agree on a precise taxonomic origin. 362 Further, calculations (see Materials \& Methods section) indicate that this putative hydrolase 363 could be present in low-abundance species, in the tail of the microbial rank-abundance curve 364 ( $\sim 0.01 \%$ relative abundance). Overall, these findings suggest that the marine microbial seed 365 bank, "a reservoir of dormant individuals that can potentially be resuscitated” (Lennon \& Jones, 366 2011), may have a potential for herbicide degradation.

367 Microbial enrichment studies that reported rapid biodegradation of diuron were conducted with a 368 rich substrate or supplemented with alternative sources of carbon and nitrogen, sometimes under 369 the form of soil or sediments (Widehem et al., 2002; Sørensen, Albers \& Aamand, 2008). From 370 this evidence, we conclude that resources may be a limiting factor for marine heterotrophs to 371 express their diuron-degrading potential in often oligotrophic marine waters (Schaffelke et al., 372 2012), as is the case in marine incubations performed without supplementation (Thomas, 373 McHugh \& Waldock, 2002; Mercurio et al., 2015). GBR microorganisms are thought to 374 metabolize nutrients from land runoff at inshore sites (Alongi \& McKinnon, 2005) and, given 375 that these sites receive high diuron and nutrient input during the wet season (Packett et al., 2009) 376 perhaps along with diuron-degrading species, we predict that heterotrophic diuron degradation 377 may be enhanced episodically in the GBR lagoon. 
378 Conclusions

379 This study used amplicon and metagenomic sequencing to evaluate the effects of a PSII herbicide

380 on the composition of entire prokaryotic communities, rather than selected species. It provides a

381 baseline for future research on the impacts of herbicides on the marine ecosystem by suggesting

382 that the effects of the PSII herbicide diuron on communities of GBR near-shore pelagic

383 prokaryotes are limited. Metagenomic evidence suggests that prokaryotic heterotrophs in the

384 marine water column may encode potential new herbicide hydrolase genes, though their

385 expression may be limited by scarce environmental resources in the dry season. The apparent

386 tolerance of marine pelagic phototrophs to diuron may have been due to the acquisition of a

387 resistance mechanism following regular exposure to this herbicide. While no PEST sequence

388 mutations in Cyanobacteria could explain this resistance in the present study, resident phages

389 carried various PEST sequence types and could act as a reservoir. In summary, many components

390 of coral reef ecosystems are stressed by herbicides from land runoff, but in contrast, the pelagic

391 microbiome that underpins the marine food web and is integral to reef functioning, may

392 represents an important buffer that mitigates the impacts of local anthropogenic and natural

393 stresses on coral reefs.

\section{Acknowledgements}

395 The authors would like to thank Elke Allers (University of Arizona) for sample extraction

396 assistance, Nicola Angel (Australian Centre for Ecogenomics) for her assistance with Illumina

397 amplicon sequencing, and Jochen Mueller (ENTOX, University of Queensland), Michael

398 Nefedov and Nancy Lachner (Australian Centre for Ecogenomics) for assistance and advice in 399 the lab.

\section{References}

Ainsworth TD., Thurber RV., Gates RD. 2010. The future of coral reefs: a microbial perspective. Trends in Ecology \& Evolution 25:233-240.

Allen MM., Turnburke AC., Lagace EA., Steinback KE. 1983. Effects of photosystem II herbicides on the photosynthetic membranes of the cyanobacterium Aphanocapsa 6308. 
Plant Physiology 71:388-392.

Alongi DM., McKinnon AD. 2005. The cycling and fate of terrestrially-derived sediments and nutrients in the coastal zone of the Great Barrier Reef shelf. Marine pollution bulletin 51:239-52.

Angly FE., Willner D., Prieto-Davó A., Edwards RA., Schmieder R., Vega-Thurber R., Antonopoulos DA., Barott K., Cottrell MT., Desnues C., Dinsdale EA., Furlan M., Haynes M., Henn MR., Hu Y., Kirchman DL., McDole T., McPherson JD., Meyer F., Miller RM., Mundt E., Naviaux RK., Rodriguez-Mueller B., Stevens R., Wegley L., Zhang L., Zhu B., Rohwer F. 2009. The GAAS metagenomic tool and its estimations of viral and microbial average genome size in four major biomes. PLoS Computational Biology 5:e1000593.

Angly FE., Dennis PG., Skarshewski A., Vanwonterghem I., Hugenholtz P., Tyson GW. 2014. CopyRighter: a rapid tool for improving the accuracy of microbial community profiles through lineage-specific gene copy number correction. Microbiome 2:11.

Angly FE., Heath C., Morgan TC., Tonin H., Rich V., Schaffelke B., Bourne DG., Tyson GW. 2015. Marine microbial communities of the Great Barrier Reef lagoon are influenced by riverine floodwaters and seasonal weather events. PeerJ Accepted.

Angly FE., Fields CJ., Tyson GW. 2014. The Bio-Community Perl toolkit for microbial ecology. Bioinformatics 30:1926-1927.

Antunes A., Alam I., Bajic VB., Stingl U. 2011. Genome sequence of Salinisphaera shabanensis, a gammaproteobacterium from the harsh, variable environment of the brine-seawater interface of the Shaban Deep in the Red Sea. Journal of Bacteriology 193:4555-4556.

Attaway HH., Paynter MJ., Camper ND. 1982. Degradation of selected phenylurea herbicides by anaerobic pond sediment. Journal of Environmental Science and Health. Part. B, Pesticides, Food Contaminants, and Agricultural Wastes 17:683-699.

Azam F., Fenchel T., Field JG., Gray JS., Meyer-Reil LA., Thingstad F. 1983. The ecological role of water-column microbes in the sea. Marine Ecology Progress Series 10:257-263.

Balakrishnan S., Takeda K., Sakugawa H. 2012. Occurrence of Diuron and Irgarol in seawater, 
sediments and planktons of Seto Inland Sea, Japan. Geochemical Journal 46:169-177.

Bellas J., Beiras R., Mariño-Balsa JC., Fernández N. 2005. Toxicity of organic compounds to marine invertebrate embryos and larvae: a comparison between the sea urchin embryogenesis bioassay and alternative test species. Ecotoxicology (London, England) 14:337-53.

Bernal A., Ear U., Kyrpides N. 2001. Genomes OnLine Database (GOLD): a monitor of genome projects world-wide. Nucleic Acids Research 29:126-127.

Bers K., Leroy B., Breugelmans P., Albers P., Lavigne R., Sørensen SR., Aamand J., Mot RD., Wattiez R., Springael D. 2011. A novel hydrolase identified by genomic-proteomic analysis of phenylurea herbicide mineralization by variovorax sp. strain SRS16. Applied and Environmental Microbiology 77:8754-8764.

Bers K., Batisson I., Proost P., Wattiez R., De Mot R., Springael D. 2013. HylA, an alternative hydrolase for Initiation of catabolism of the phenylurea herbicide linuron in Variovorax sp. strains. Applied and Environmental Microbiology 79:5258-5263.

Bettini P., McNally S., Sevignac M., Darmency H., Gasquez J., Dron M. 1987. Atrazine resistance in Chenopodium album low and high levels of resistance to the herbicide are related to the same chloroplast psbA gene mutation. Plant Physiology 84:1442-1446.

Brodie JE., Kroon FJ., Schaffelke B., Wolanski EC., Lewis SE., Devlin MJ., Bohnet IC., Bainbridge ZT., Waterhouse J., Davis AM. 2012. Terrestrial pollutant runoff to the Great Barrier Reef: An update of issues, priorities and management responses. Marine Pollution Bulletin 65:81-100.

Brusslan J., Haselkorn R. 1989. Resistance to the photosystem II herbicide diuron is dominant to sensitivity in the cyanobacterium Synechococcus sp. PCC7942. The EMBO Journal 8:1237-1245.

Camacho C., Coulouris G., Avagyan V., Ma N., Papadopoulos J., Bealer K., Madden TL. 2009. BLAST+: architecture and applications. BMC Bioinformatics 10:421.

Cole JR., Wang Q., Cardenas E., Fish J., Chai B., Farris RJ., Kulam-Syed-Mohideen AS., McGarrell DM., Marsh T., Garrity GM., Tiedje JM. 2009. The Ribosomal Database 
Project: improved alignments and new tools for rRNA analysis. Nucleic Acids Research 37:D141-D145.

Cullington JE., Walker A. 1999. Rapid biodegradation of diuron and other phenylurea herbicides by a soil bacterium. Soil Biology and Biochemistry 31:677-686.

De’ath G., Fabricius KE., Sweatman H., Puotinen M. 2012. The 27-year decline of coral cover on the Great Barrier Reef and its causes. Proceedings of the National Academy of Sciences 109:17995-17999.

el-Deeb BA., Soltan SM., Ali AM., Ali KA. 2000. Detoxication of the herbicide diuron by Pseudomonas sp. Folia Microbiologica 45:211-216.

Dellamatrice PM., Monteiro RTR. 2004. Isolation of diuron-degrading bacteria from treated soil. Brazilian Archives of Biology and Technology 47:999-1003.

Deng X., Gao K., Sun J. 2012. Physiological and biochemical responses of Synechococcus sp. PCC7942 to Irgarol 1051 and diuron. Aquatic Toxicology 122-123:113-119.

Dinsdale EA., Pantos O., Smriga S., Edwards RA., Angly F., Wegley L., Hatay M., Hall D., Brown E., Haynes M., Krause L., Sala E., Sandin SA., Thurber RV., Willis BL., Azam F., Knowlton N., Rohwer F. 2008. Microbial ecology of four coral atolls in the northern Line Islands. PLoS ONE 3:e1584.

Dixon P. 2003. VEGAN, a package of R functions for community ecology. Journal of Vegetation Science 14:927-930.

Dove SG., Kline DI., Pantos O., Angly FE., Tyson GW., Hoegh-Guldberg O. 2013. Future reef decalcification under a business-as-usual CO2 emission scenario. Proceedings of the National Academy of Sciences 110:15342-15347.

Eddy SR. 2011. Accelerated profile HMM searches. PLoS Comput Biol 7:e1002195.

Edgar RC. 2013. UPARSE: highly accurate OTU sequences from microbial amplicon reads. Nature Methods 10:996-998.

Ellis PA., Camper ND. 1982. Aerobic degradation of diuron by aquatic microorganisms. Journal of Environmental Science and Health, Part B 17:277-289.

Eriksson KM., Clarke AK., Franzen L-G., Kuylenstierna M., Martinez K., Blanck H. 2009. 
Community-level analysis of psbA gene sequences and Irgarol tolerance in marine periphyton. Applied and Environmental Microbiology 75:897-906.

Fabricius KE. 2005. Effects of terrestrial runoff on the ecology of corals and coral reefs: review and synthesis. Marine Pollution Bulletin 50:125-146.

Faÿ F., Linossier I., Carteau D., Dheilly A., Silkina A., Vallée-Rééhel K. 2010. Booster biocides and microfouling. Biofouling 26:787-798.

Fenchel T. 2008. The microbial loop - 25 years later. Journal of experimental marine biology and ecology 366:99-103.

Fierer N., Nemergut D., Knight R., Craine JM. 2010. Changes through time: integrating microorganisms into the study of succession. Research in Microbiology 161:635-642.

Flores F., Collier CJ., Mercurio P., Negri AP. 2013. Phytotoxicity of four photosystem II herbicides to tropical seagrasses. PLoS ONE 8:e75798.

Gadkari D. 1988. Assessment of the effects of the photosynthesis-inhibiting herbicides Diuron, DCMU, metamitron and metribuzin on growth and nitrogenase activity of Nostoc muscorum and a new cyanobacterial isolate, strain G4. 6:50-54.

Haft DH., Selengut JD., White O. 2003. The TIGRFAMs database of protein families. Nucleic Acids Research 31:371-373.

Haynes D., Ralph P., Prange J., Dennison B. 2000. The impact of the herbicide diuron on photosynthesis in three species of tropical seagrass. Marine Pollution Bulletin 41:288293.

Haynes D., Müller J., Carter S. 2000. Pesticide and herbicide residues in sediments and seagrasses from the Great Barrier Reef world heritage area and Queensland coast. Marine Pollution Bulletin 41:279-287.

Hughes TP., Graham NAJ., Jackson JBC., Mumby PJ., Steneck RS. 2010. Rising to the challenge of sustaining coral reef resilience. Trends in Ecology \& Evolution 25:633-642.

Jones R., Muller J., Haynes D., Schreiber U. 2003. Effects of herbicides diuron and atrazine on corals of the Great Barrier Reef, Australia. Marine Ecology Progress Series 251:153-167.

Jones RJ. 2004. Testing the "photoinhibition” model of coral bleaching using chemical inhibitors. 
Marine ecology. Progress series 284:133-145.

Kennedy K., Schroeder T., Shaw M., Haynes D., Lewis S., Bentley C., Paxman C., Carter S., Brando VE., Bartkow M., Hearn L., Mueller JF. 2012a. Long term monitoring of photosystem II herbicides - Correlation with remotely sensed freshwater extent to monitor changes in the quality of water entering the Great Barrier Reef, Australia. Marine Pollution Bulletin 65:292-305.

Kennedy K., Devlin M., Bentley C., Lee-Chue K., Paxman C., Carter S., Lewis SE., Brodie J., Guy E., Vardy S., Martin KC., Jones A., Packett R., Mueller JF. 2012b. The influence of a season of extreme wet weather events on exposure of the World Heritage Area Great Barrier Reef to pesticides. Marine Pollution Bulletin 64:1495-1507.

Khurana JL., Jackson CJ., Scott C., Pandey G., Horne I., Russell RJ., Herlt A., Easton CJ., Oakeshott JG. 2009. Characterization of the phenylurea hydrolases A and B: founding members of a novel amidohydrolase subgroup. Biochemical Journal 418:431.

Legrand H., Herlory O., Guarini J-M., Blanchard G., Richard P. 2006. Inhibition of microphytobenthic photosynthesis by the herbicides atrazine and diuron. Cahiers de Biologie Marine 47:39-45.

Lema KA., Willis BL., Bourne DG. 2012. Corals form characteristic associations with symbiotic nitrogen-fixing Bacteria. Applied and Environmental Microbiology 78:3136-3144.

Lennon JT., Jones SE. 2011. Microbial seed banks: the ecological and evolutionary implications of dormancy. Nature Reviews Microbiology 9:119-130.

Lesser MP., Mazel CH., Gorbunov MY., Falkowski PG. 2004. Discovery of symbiotic nitrogenfixing Cyanobacteria in corals. Science 305:997-1000.

Lewis SE., Brodie JE., Bainbridge ZT., Rohde KW., Davis AM., Masters BL., Maughan M., Devlin MJ., Mueller JF., Schaffelke B. 2009. Herbicides: A new threat to the Great Barrier Reef. Environmental Pollution 157:2470-2484.

Lindell D., Sullivan MB., Johnson ZI., Tolonen AC., Rohwer F., Chisholm SW. 2004. Transfer of photosynthesis genes to and from Prochlorococcus viruses. Proceedings of the National Academy of Sciences of the United States of America 101:11013-11018. 
Lürling M., Roessink I. 2006. On the way to cyanobacterial blooms: Impact of the herbicide metribuzin on the competition between a green alga (Scenedesmus) and a cyanobacterium (Microcystis). Chemosphere 65:618-626.

Magnusson M., Heimann K., Ridd M., Negri AP. 2012. Chronic herbicide exposures affect the sensitivity and community structure of tropical benthic microalgae. Marine Pollution Bulletin 65:363-372.

Magnusson M., Heimann K., Negri AP. 2008. Comparative effects of herbicides on photosynthesis and growth of tropical estuarine microalgae. Marine Pollution Bulletin 56:1545-1552.

Mai H., Morin B., Pardon P., Gonzalez P., Budzinski H., Cachot J. 2013. Environmental concentrations of irgarol, diuron and S-metolachlor induce deleterious effects on gametes and embryos of the Pacific oyster, Crassostrea gigas. Marine Environmental Research 89:1-8.

McDonald D., Price MN., Goodrich J., Nawrocki EP., DeSantis TZ., Probst A., Andersen GL., Knight R., Hugenholtz P. 2012. An improved Greengenes taxonomy with explicit ranks for ecological and evolutionary analyses of bacteria and archaea. The ISME Journal 6:610-618.

McMahon K., Bengtson Nash S., Eaglesham G., Müller JF., Duke NC., Winderlich S. 2005. Herbicide contamination and the potential impact to seagrass meadows in Hervey Bay, Queensland, Australia. Marine Pollution Bulletin 51:325-334.

Mengistu LW., Mueller-Warrant GW., Liston A., Barker rE. 2000. psbA Mutation (valine219 to isoleucine) in Poa annua resistant to metribuzin and diuron. Pest Management Science 56:209-217.

Mercurio P., Mueller JF., Eaglesham G., Flores F., Negri AP. 2015. Herbicide persistence in seawater simulation experiments. PLoS ONE 10:e0136391.

Metz JG., Pakrasi HB., Seibert M., Arntzer CJ. 1986. Evidence for a dual function of the herbicide-binding D1 protein in photosystem II. FEBS Letters 205:269-274.

Mhadhbi L., Beiras R. 2012. Acute toxicity of seven selected pesticides (alachlor, atrazine, 
dieldrin, diuron, pirimiphos-methyl, chlorpyrifos, diazinon) to the marine fish (Turbot, Psetta maxima). Water, Air, \& Soil Pollution 223:5917-5930.

Mitchell C., Brodie J., White I. 2005. Sediments, nutrients and pesticide residues in event flow conditions in streams of the Mackay Whitsunday Region, Australia. Marine Pollution Bulletin 51:23-36.

Molander S., Blanck H. 1992. Detection of pollution-induced community tolerance (PICT) in marine periphyton communities established under diuron exposure. Aquatic Toxicology 22:129-143.

Moncada A. 2004. Environmental fate of diuron. Department of Pesticide Regulation Report, Sacramento, CA.

Ngigi A., Getenga Z., Boga H., Ndalut P. 2011. Biodegradation of phenylurea herbicide diuron by microorganisms from long-term-treated sugarcane-cultivated soils in Kenya. Toxicological \& Environmental Chemistry 93:1623-1635.

Okamura H. 2002. Photodegradation of the antifouling compounds Irgarol 1051 and Diuron released from a commercial antifouling paint. Chemosphere 48:43-50.

Packett R., Dougall C., Rohde K., Noble R. 2009. Agricultural lands are hot-spots for annual runoff polluting the southern Great Barrier Reef lagoon. Marine Pollution Bulletin 58:976-986.

Pandolfi JM., Bradbury RH., Sala E., Hughes TP., Bjorndal KA., Cooke RG., McArdle D., McClenachan L., Newman MJH., Paredes G., Warner RR., Jackson JBC. 2003. Global trajectories of the long-term decline of coral reef ecosystems. Science 301:955-958.

Peng Y., Leung HCM., Yiu SM., Chin FYL. 2012. IDBA-UD: a de novo assembler for single-cell and metagenomic sequencing data with highly uneven depth. Bioinformatics 28:1420 1428.

Pesce S., Martin-Laurent F., Rouard N., Robin A., Montuelle B. 2010. Evidence for adaptation of riverine sediment microbial communities to diuron mineralization: incidence of runoff and soil erosion. Journal of Soils and Sediments 10:698-707.

Pesce S., Beguet J., Rouard N., Devers-Lamrani M., Martin-Laurent F. 2012. Response of a 
diuron-degrading community to diuron exposure assessed by real-time quantitative PCR monitoring of phenylurea hydrolase A and B encoding genes. Applied Microbiology and Biotechnology 97:1661-1668.

Proia L., Morin S., Peipoch M., Romaní AM., Sabater S. 2011. Resistance and recovery of river biofilms receiving short pulses of Triclosan and Diuron. Science of The Total Environment 409:3129-3137.

Quast C., Pruesse E., Yilmaz P., Gerken J., Schweer T., Yarza P., Peplies J., Glockner FO. 2012. The SILVA ribosomal RNA gene database project: improved data processing and webbased tools. Nucleic Acids Research 41:D590-D596.

R Foundation for Statistical Computing, Vienna, Austria. R: A language and environment for statistical computing.

Ricart M., Barceló D., Geiszinger A., Guasch H., Alda ML de., Romaní AM., Vidal G., Villagrasa M., Sabater S. 2009. Effects of low concentrations of the phenylurea herbicide diuron on biofilm algae and bacteria. Chemosphere 76:1392-1401.

Rohwer F., Seguritan V., Azam F., Knowlton N. 2002. Diversity and distribution of coralassociated bacteria. Marine ecology. Progress series 243:1-10.

Rost B. 1999. Twilight zone of protein sequence alignments. Protein Engineering 12:85-94.

Rumble SM., Lacroute P., Dalca AV., Fiume M., Sidow A., Brudno M. 2009. SHRiMP: Accurate mapping of short color-space reads. PLoS Comput Biol 5:e1000386.

Safi J., Awad Y., El-Nahhal Y. 2014. Bioremediation of diuron in soil environment: influence of cyanobacterial mat. American Journal of Plant Sciences 05:1081-1089.

Sandin SA., Smith JE., DeMartini EE., Dinsdale EA., Donner SD., Friedlander AM., Konotchick T., Malay M., Maragos JE., Obura D., Pantos O., Paulay G., Richie M., Rohwer F., Schroeder RE., Walsh S., Jackson JBC., Knowlton N., Sala E., Ahmed N. 2008. Baselines and degradation of coral reefs in the Northern Line Islands. PLoS ONE 3:e1548.

Schaffelke B., Carleton J., Skuza M., Zagorskis I., Furnas MJ. 2012. Water quality in the inshore Great Barrier Reef lagoon: Implications for long-term monitoring and management. Marine Pollution Bulletin 65:249-260. 
Segata N., Izard J., Waldron L., Gevers D., Miropolsky L., Garrett WS., Huttenhower C. 2011. Metagenomic biomarker discovery and explanation. Genome Biology 12:R60.

Selenska-Pobell S., Radeva G. 2004. Bacterial diversity in water samples from two Uranium mill tailings as revealed by $16 \mathrm{~S}$ rDNA retrieval. Comptes Rendus de l'Academie Bulgare des Sciences (1991) 57:85-90.

Sharon I., Tzahor S., Williamson S., Shmoish M., Man-Aharonovich D., Rusch DB., Yooseph S., Zeidner G., Golden SS., Mackey SR., Adir N., Weingart U., Horn D., Venter JC., MandelGutfreund Y., Béjà O. 2007. Viral photosynthetic reaction center genes and transcripts in the marine environment. The ISME Journal 1:492-501.

Shaw M., Furnas MJ., Fabricius K., Haynes D., Carter S., Eaglesham G., Mueller JF. 2010. Monitoring pesticides in the Great Barrier Reef. Marine Pollution Bulletin 60:113-122.

Shaw CM., Brodie J., Mueller JF. 2012. Phytotoxicity induced in isolated zooxanthellae by herbicides extracted from Great Barrier Reef flood waters. Marine Pollution Bulletin 65:355-362.

Shaw M., Müller JF. 2005. Preliminary evaluation of the occurrence of herbicides and PAHs in the Wet Tropics region of the Great Barrier Reef, Australia, using passive samplers. Marine Pollution Bulletin 51:876-881.

Sinning I. 1992. Herbicide binding in the bacterial photosynthetic reaction center. Trends in Biochemical Sciences 17:150-154.

Smith R., Middlebrook R., Turner R., Huggins R., Vardy S., Warne M. 2012. Large-scale pesticide monitoring across Great Barrier Reef catchments - Paddock to reef integrated monitoring, modelling and reporting program. Marine Pollution Bulletin 65:117-127.

Sørensen SR., Albers CN., Aamand J. 2008. Rapid mineralization of the phenylurea herbicide diuron by Variovorax sp. strain SRS16 in pure culture and within a two-member consortium. Applied and Environmental Microbiology 74:2332-2340.

Stasinakis AS., Kotsifa S., Gatidou G., Mamais D. 2009. Diuron biodegradation in activated sludge batch reactors under aerobic and anoxic conditions. Water Research 43:14711479. 
Sugrue E., Fraser NJ., Hopkins DH., Carr PD., Khurana JL., Oakeshott JG., Scott C., Jackson CJ. 2015. Evolutionary expansion of the amidohydrolase superfamily in bacteria in response to synthetic compounds: the molinate and diuron hydrolases. Applied and Environmental Microbiology:AEM.04016-14.

Sumpono, Perotti P., Belan A., Forestier C., Lavedrine B., Bohatier J. 2003. Effect of diuron on aquatic bacteria in laboratory-scale wastewater treatment ponds with special reference to Aeromonas species studied by colony hybridization. Chemosphere 50:445-455.

Suzuki M., Preston C., Béjà O., de la Torre J., Steward G., DeLong E. 2004. Phylogenetic screening of ribosomal RNA gene-containing clones in bacterial artificial chromosome (BAC) libraries from different depths in Monterey Bay. Microbial Ecology 48:473-488.

Thomas KV., McHugh M., Waldock M. 2002. Antifouling paint booster biocides in UK coastal waters: inputs, occurrence and environmental fate. Science of The Total Environment 293:117-127.

Thurber RV., Willner-Hall D., Rodriguez-Mueller B., Desnues C., Edwards RA., Angly F., Dinsdale E., Kelly L., Rohwer F. 2009. Metagenomic analysis of stressed coral holobionts. Environmental Microbiology 11:2148-2163.

Tlili A., Dorigo U., Montuelle B., Margoum C., Carluer N., Gouy V., Bouchez A., Bérard A. 2008. Responses of chronically contaminated biofilms to short pulses of diuron: An experimental study simulating flooding events in a small river. Aquatic Toxicology 87:252-263.

Tlili A., Montuelle B., Bérard A., Bouchez A. 2011. Impact of chronic and acute pesticide exposures on periphyton communities. Science of The Total Environment 409:2102-2113.

Turnbull GA., Ousley M., Walker A., Shaw E., Morgan JA. 2001. Degradation of substituted phenylurea herbicides by Arthrobacter globiformis strain D47 and characterization of a plasmid-associated hydrolase gene, puhA. Applied and Environmental Microbiology 67:2270-2275.

Villaverde J., Posada-Baquero R., Rubio-Bellido M., Laiz L., Saiz-Jimenez C., Sanchez-Trujillo MA., Morillo E. 2012. Enhanced mineralization of diuron using a cyclodextrin-based 
bioremediation technology. Journal of Agricultural and Food Chemistry 60:9941-9947. Voth DE., Heinzen RA. 2007. Lounging in a lysosome: the intracellular lifestyle of Coxiella burnetii. Cellular Microbiology 9:829-840.

Waterhouse AM., Procter JB., Martin DMA., Clamp M., Barton GJ. 2009. Jalview Version 2-a multiple sequence alignment editor and analysis workbench. Bioinformatics 25:1189_ 1191.

Webster NS., Soo R., Cobb R., Negri AP. 2011. Elevated seawater temperature causes a microbial shift on crustose coralline algae with implications for the recruitment of coral larvae. The ISME Journal 5:759-770.

Widehem P., Ait-Aïssa S., Tixier C., Sancelme M., Veschambre H., Truffaut N. 2002. Isolation, characterization and diuron transformation capacities of a bacterial strain Arthrobacter sp. N2. Chemosphere 46:527-534.

Worden AZ., Lee J-H., Mock T., Rouzé P., Simmons MP., Aerts AL., Allen AE., Cuvelier ML., Derelle E., Everett MV., Foulon E., Grimwood J., Gundlach H., Henrissat B., Napoli C., McDonald SM., Parker MS., Rombauts S., Salamov A., Dassow PV., Badger JH., Coutinho PM., Demir E., Dubchak I., Gentemann C., Eikrem W., Gready JE., John U., Lanier W., Lindquist EA., Lucas S., Mayer KFX., Moreau H., Not F., Otillar R., Panaud O., Pangilinan J., Paulsen I., Piegu B., Poliakov A., Robbens S., Schmutz J., Toulza E., Wyss T., Zelensky A., Zhou K., Armbrust EV., Bhattacharya D., Goodenough UW., Peer YV de., Grigoriev IV. 2009. Green evolution and dynamic adaptations revealed by genomes of the marine picoeukaryotes Micromonas. Science 324:268-272.

Xu H., Lu A., Yu H., Sun J., Shen M. 2013. Distribution of diuron in coastal seawater and sediments from west sea area of Zhoushan island. Open Journal of Marine Science 03:140-147.

Zeidner G., Bielawski JP., Shmoish M., Scanlan DJ., Sabehi G., Béjà O. 2005. Potential photosynthesis gene recombination between Prochlorococcus and Synechococcus via viral intermediates. Environmental Microbiology 7:1505-1513. 
1

Heatmap showing the relative abundance of microbial genera over the one-year Cape Ferguson diuron incubations.

The four incubation conditions are control+dark (C_D), control+light (C_L), diuron+dark (D_D) and diuron+light (D_L). The three replicates of each incubation condition were averaged and only microbial genera reaching $1 \%$ are indicated. 


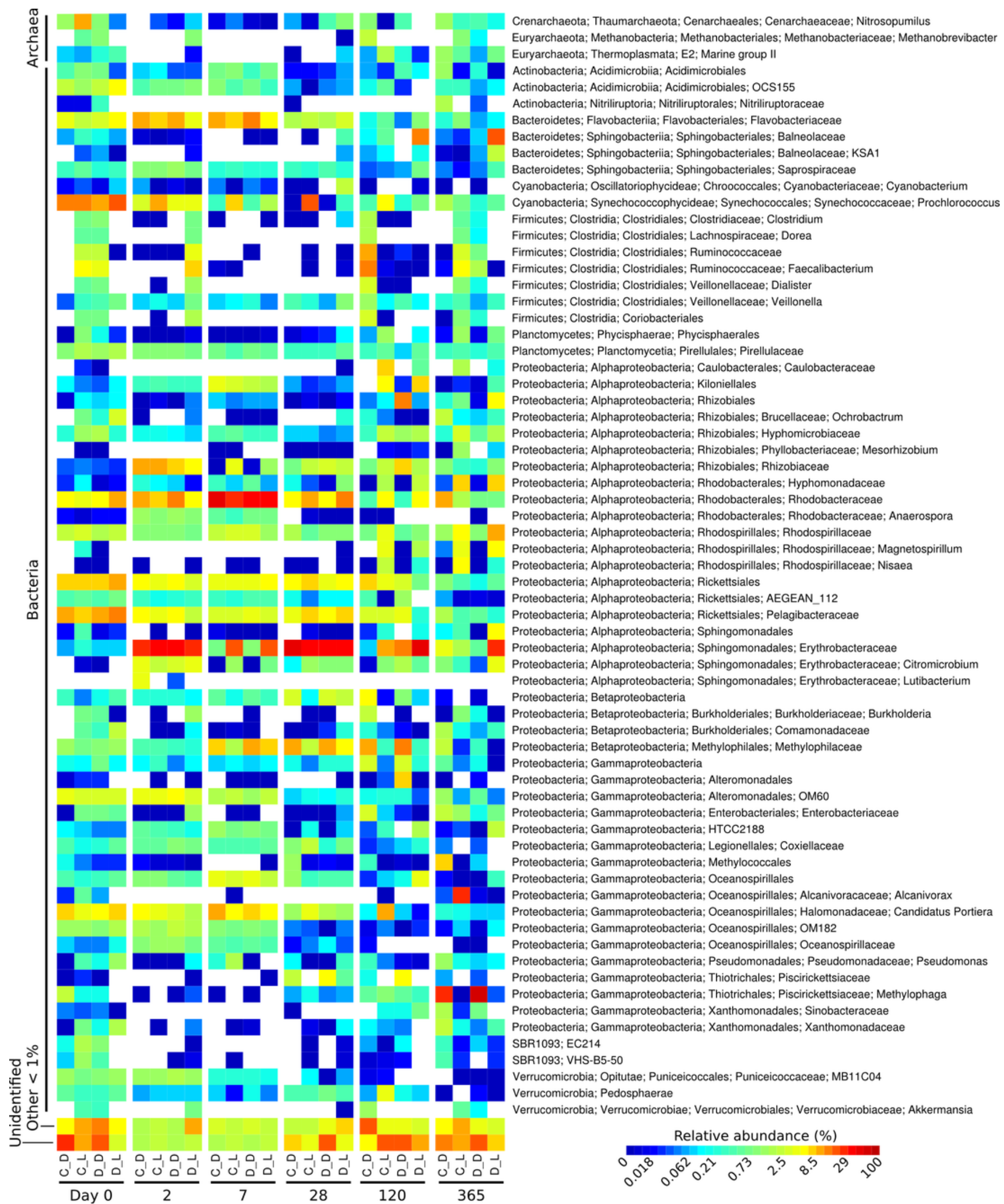


2

OTU-level RDA of the microbiomes (Hellinger-based) in the Cape Ferguson diuron incubations.

OTUs are indicated by a red cross and the Greengenes taxonomic affiliation of the most discriminating is shown. Circle size is proportional to incubation time (sampling day). Environmental factors are green arrows depicting light amount in the light and dark treatments, incubation time and measured diuron concentration. Asterisks denote environmental factors that are statistically significant (PERMANOVA; $p<0.05$ ). Samples from day 2 and 7 were omitted from this analysis because diuron was not measured on these days. 


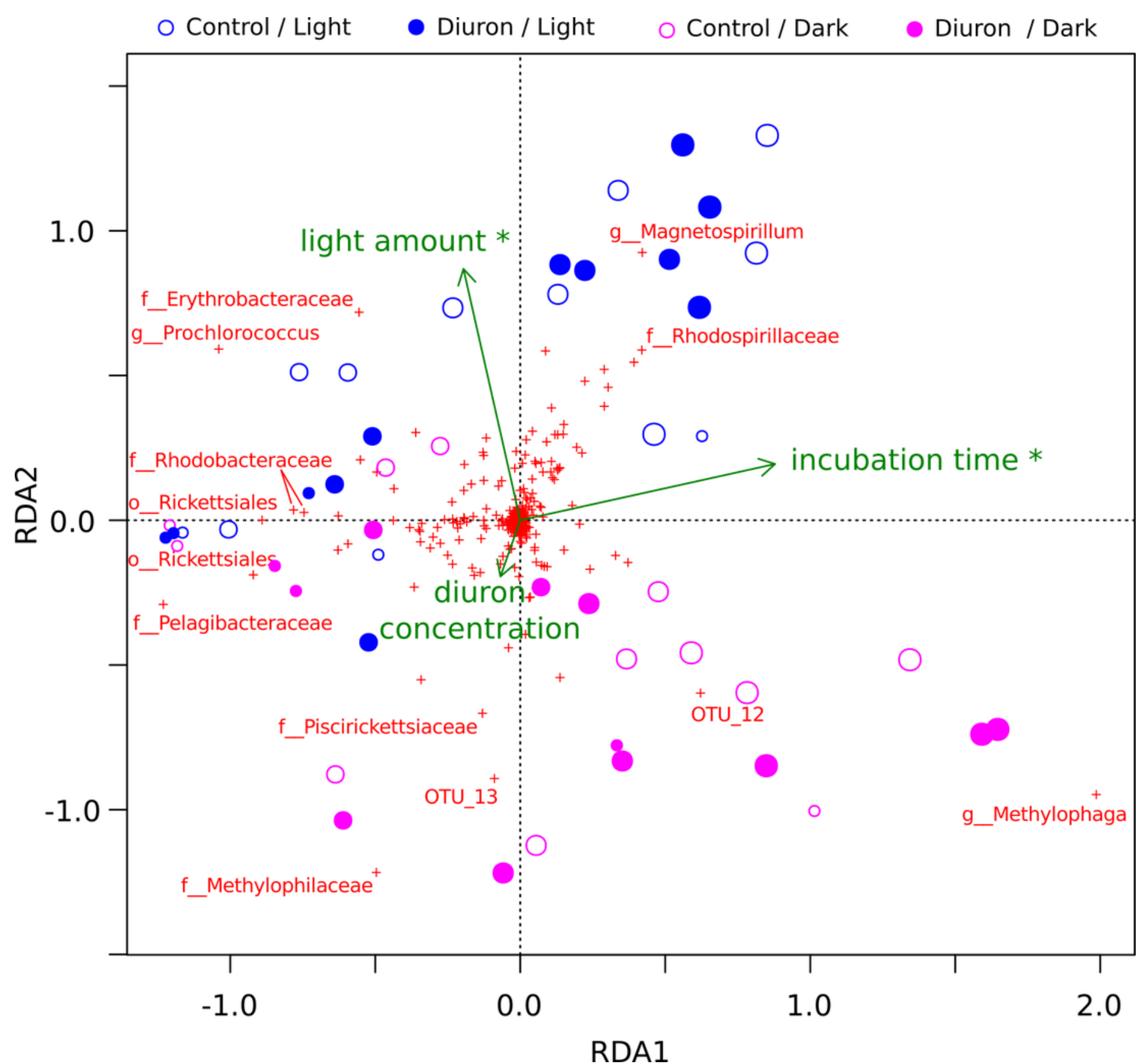


Sequence alignment of the PsbA proteins predicted from Dunk Island metagenomic scaffolds.

Residues are colored based on the Clustal X scheme. Locations previously correlated with herbicide resistance are indicated by a box. The bold sequence corresponds to PEST type 11, implicated in resistance against the irgarol PSII herbicide. The bottom panel represents the number of conserved amino acids at each position and their consensus and the column on the right the BLASTN taxonomic classification of the scaffolds.

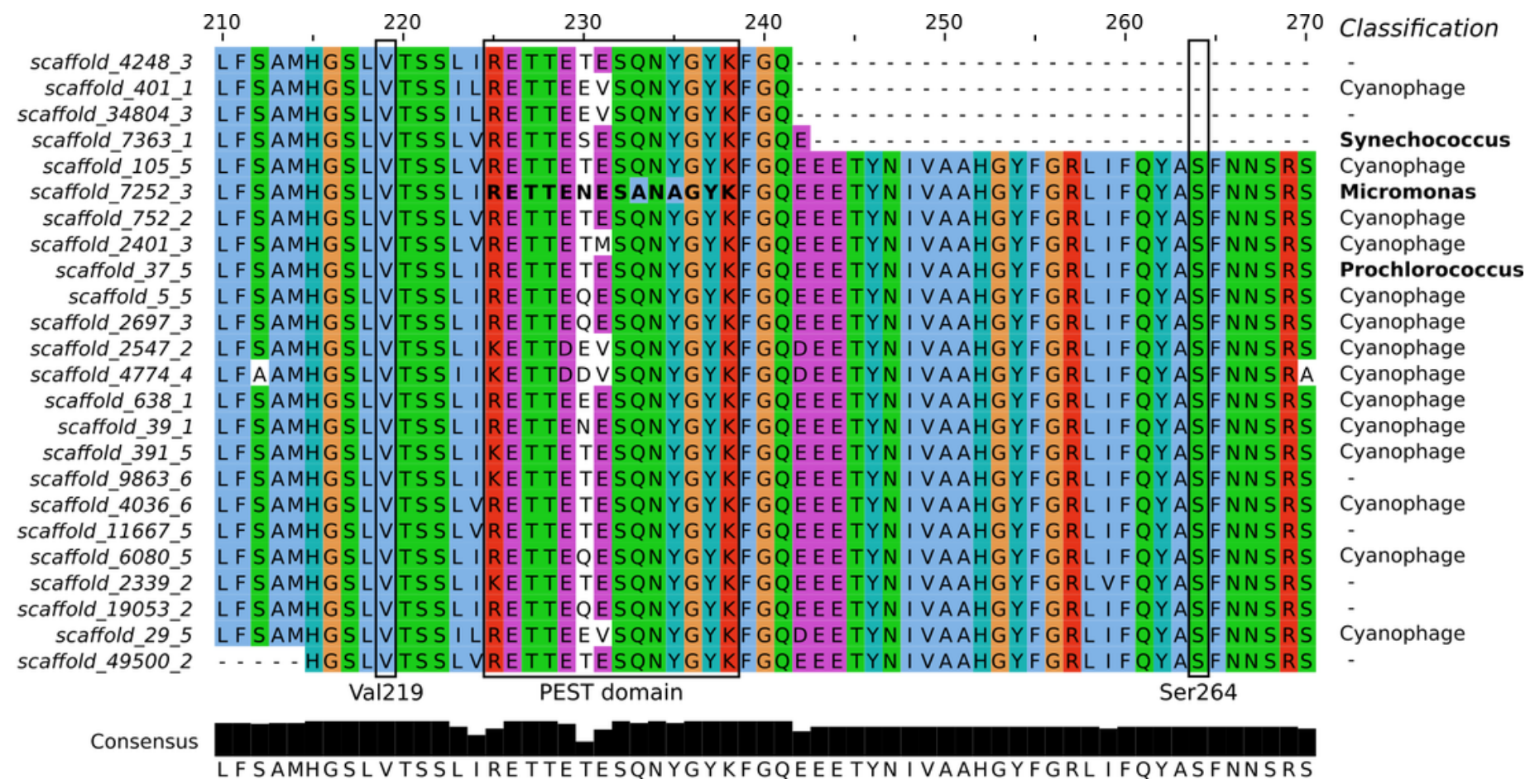

